\title{
The influence of metabolic imbalances and oxidative stress on the outcome of critically ill polytrauma patients: a review
}

\author{
Alexandru Florin Rogobete ${ }^{1,2^{*}}$ D, Dorel Sandesc ${ }^{1,2}$, Marius Papurica ${ }^{1,2}$, Emil Robert Stoicescu', Sonia Elena Popovici ${ }^{1}$, \\ Lavinia Melania Bratu ${ }^{3}$, Corina Vernic ${ }^{1}$, Adriana Mariana Sas ${ }^{1}$, Adrian Tudor Stan ${ }^{4}$ and Ovidiu Horea Bedreag ${ }^{1,2}$
}

\begin{abstract}
The critically ill polytrauma patient presents with a series of associated pathophysiologies secondary to the traumatic injuries. The most important include systemic inflammatory response syndrome (SIRS), sepsis, oxidative stress (OS), metabolic disorders, and finally multiple organ dysfunction syndrome (MODS) and death. The poor outcome of these patients is related to the association of the aforementioned pathologies. The nutrition of the critically ill polytrauma patient is a distinct challenge because of the rapid changes in terms of energetic needs associated with hypermetabolism, sepsis, SIRS, and OS. Moreover, it has been proven that inadequate nutrition can prolong the time spent on a mechanical ventilator and the length of stay in an intensive care unit (ICU). A series of mathematical equations can predict the energy expenditure (EE), but they have disadvantages, such as the fact that they cannot predict the EE accurately in the case of patients with hypermetabolism. Indirect calorimetry (IC) is another method used for evaluating and monitoring the energy status of critically ill patients. In this update paper, we present a series of pathophysiological aspects associated with the metabolic disaster affecting the critically ill polytrauma patient. Furthermore, we present different non-invasive monitoring methods that could help the intensive care physician in the adequate management of this type of patient.
\end{abstract}

Keywords: Critically ill, Energy expenditure, Indirect calorimetry, Metabolic disaster, Oxidative stress, Overfeeding, Underfeeding, Polytrauma

\section{Background}

Critically ill polytrauma patients show a series of associated pathophysiologies that can increase both morbidity and mortality $[1,2]$. The most frequent and best researched of these pathologies are systemic inflammatory response syndrome (SIRS), acute respiratory distress syndrome (ARDS), sepsis, and multiple organ dysfunction syndrome (MODS) [3-6]. Moreover, secondary to these pathologies, these patients quickly develop oxidative stress (OS) and severe metabolic disorders characterized in particular by hypermetabolism [7, 8]. Recent studies have shown a strong link between nutritional imbalance and the outcome

\footnotetext{
* Correspondence: alexandru.rogobete@umft.ro

${ }^{1}$ Faculty of Medicine, Victor Babes University of Medicine and Pharmacy, Str. Eftimie Murgu Nr. 2, Timisoara 300041, Timis, Romania

${ }^{2}$ Clinic of Anaesthesia and Intensive Care, Emergency County Hospital "Pius

Brinzeu", Bd. Liviu Rebreanu Nr.156, Timisoara 300736, Timis, Romania

Full list of author information is available at the end of the article
}

of critical patients. Huang et al. reported that over $90 \%$ of critical patients are malnourished 14 days after admission to the intensive care unit (ICU) [9].

From a metabolic perspective, a critically ill polytrauma patient is characterized by an increase in energy expenditure (EE), an increase in insulin resistance, and a decrease in protein synthesis. By drawing together the pathophysiological aspects of primary and secondary traumatic injuries, clinical aspects of muscle weakness, increased immobility, hard recovery, and increased ventilation time are described [10-13].

To optimize nutritional therapy according to the needs of each patient, a number of monitoring methods have been developed. One of the best known is indirect calorimetry (IC), based mainly on monitoring oxygen consumption $\left(\mathrm{VO}_{2}\right)$ and carbon dioxide production $\left(\mathrm{VCO}_{2}\right)[10,14]$. 
In this updated paper, we present an overview of the pathologies associated with the metabolic disorders developed in critically ill polytrauma patients. We also present several methods that are useful in the monitoring of the nutritional balance of these patients, specifically of EE.

\section{Review}

\section{Pathophysiological and genetic-related aspects}

Critically ill polytrauma patients present with several complex disorders that lead to a significant decrease in survival rate (Fig. 1).

In terms of metabolic status, in the event of inappropriate nutritional therapy, critically ill patients will suffer from either malnutrition or overfeeding. Smallwood et al. conducted a study on the determination of the resting energy expenditure (REE) of critically ill pediatric patients by IC using E-COVX gas exchange modules (GE Healthcare, Waukesha, WI). The Weir equation was used for REE calculation $\left(\mathrm{REE}=\left[\mathrm{VO}_{2} \times 3.941+\mathrm{VCO}_{2} \times 1.106\right] \times\right.$ 1440). The energy supply for $63 \%$ of patients was under the measured $\mathrm{EE}, 16 \%$ met the measured $\mathrm{EE}$ requirement, and $21 \%$ were overfed above the measured EE [15].

Tavladaki et al. conducted a study regarding the evaluation and monitoring of metabolic imbalances using cellular biomarkers, such as the expression of ATP, $\mathrm{NO}_{2}^{-}$, and continuous monitoring for $\mathrm{EE}$, using the gas module E-COVX (GE Healthcare, Helsinki, Finland) in critical patients with sepsis and post-traumatic SIRS. Following that study, it was shown that patients with sepsis and SIRS present with a predominantly hypometabolic profile. Moreover, patients with sepsis presented lower production of ATP than healthy controls ( $184 \pm 133$ vs. $895 \pm 863 \mathrm{nM})[16]$.

Oxidative stress (OS) is another pathology found in a high percentage of critically ill patients. Numerous studies have highlighted the impact of OS on the outcome of these patients $[17,18]$. They have reported numerous OSassociated pathologies that are responsible for increased morbidity and mortality rates in critically ill polytrauma patients. Several studies have shown that increased OS is associated with a major metabolic imbalance [19].

From a biochemical perspective, the most important free radicals are the reactive oxygen species (ROS), the reactive lipid species (RLS), and the reactive nitrogen species (RNS). Under physiological conditions, the human body is protected from OS by the endogenous enzymatic system, represented by glutathiones (GSHs), catalases (CATs), glutaredoxins (Grxs), thioredoxins (Trxs), and peroxiredoxins (Prxs) [20-22]. Together with the augmentation of the redox status, a series of biological cellular systems are affected, such as DNA and protein destruction or the lipid

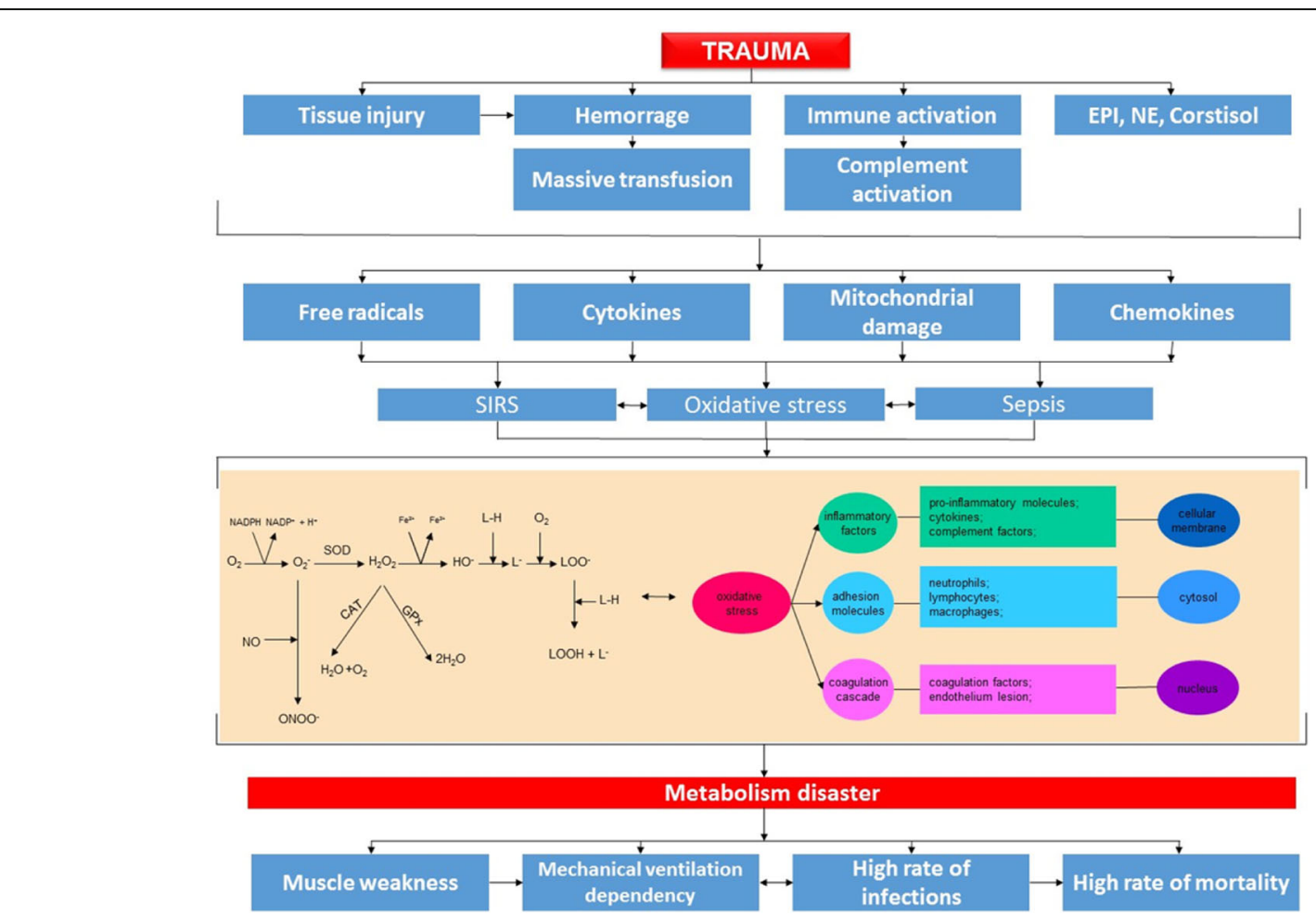

Fig. 1 Pathophysiologies associated with trauma and their influence on metabolic disaster. Pathophysiological links between trauma, proinflammatory status, pro-oxidative status (oxidative stress), and clinical outcomes. EPI epinephrine, NE norepinephrine, SIRS systemic inflammatory response syndrome 
status, through their destruction and the implicit production of new free radical species. Regarding the evaluation and monitoring of OS using specific serum biomarkers, the most representative to date are malondialdehyde (MDA) and 4-hydroxynonenal (4-HNE) for lipid peroxidation, while for protein peroxidation, the most important ones are carbonyl groups and nitrotyrosine [23-26]. Other biomarkers that could offer answers in regard to prooxidative and proinflammatory status are specific cytokines such as interleukin 1 (IL-1), interleukin 2 (IL-2), interleukin 6 (IL-6), interleukin 8 (IL-8), and tumor necrosis factor alpha (TNF- $\alpha$ ). Furthermore, specific biomarkers for OS, such as glutathione disulfide (GSSG) and reduced glutathione (GSSH), have also been reported [27-29]. However, at present, there are a number of studies that describe other methods for evaluating OS. Bjugstad et al. studied the oxidation-reduction potential (ORP) in patients with traumatic brain injury. They measured the static ORP (sORP) to reflect oxidative stress and the induced capacity ORP (icORP) to reflect induced oxidative stress. In that study, they showed that icORP at day 4 is useful for determining the clinical outcome $(p<0.05)$. Analyses were performed using the RedoxSYS system to measure the ability to transfer electrons from an antioxidant to an oxidant [30].

Critically ill polytrauma patients present an increased proinflammatory status, leading to an increased incidence of multiple organ dysfunction syndrome (MODS) development in such cases [5]. Under these conditions, a number of metabolic disorders and biochemical mechanisms are severely affected due to the aggressive reactions induced by free radicals (FRs) and other cellular proinflammatory mediators. An important protection factor for the cell is glutamine. In accentuated prooxidative and proinflammatory conditions, the serum levels of glutamine decrease, leading to the need for exogenous administration. Grintescu et al. studied the effects induced by the administration of specific nutrients in critically ill patients experiencing hyperglycemia. After the study, they highlighted that glutamine supplementation is associated with a significant decrease in the incidence of hyperglycemia episodes. They also reported a significant decrease in the daily insulin dose required for the stabilization of blood glucose levels [31]. In the case of a critically ill patient, the metabolic balance is maintained through complex mechanisms of energy substrate use. Pathophysiological changes are significantly reflected in the metabolic balance and therefore take their toll on the clinical aspects of these patients. From a clinical perspective, we can identify a number of changes in terms of drastic increases in $\mathrm{EE}$ and in glucose concentration and a decrease in muscle mass. The inflammatory response is also involved in modifying the metabolism in these patients. Albacker et al. conducted a similar study, which showed a decrease in IL-6, IL-8, and TNF- $\alpha$ concentrations in patients who had insulin administered to modulate the metabolic balance [32]. Jeschke et al. conducted a similar study in patients with severe burns and identified a normalization of proinflammatory factors by modulating the metabolism through insulin therapy [33].

Table 1 summarizes the clinical consequences of inadequate nutrition in critically ill patients.

A high number of genetic factors are involved in the metabolic balance. Thus, a series of biochemical and genetic systems responsible for the metabolic mechanisms of cholesterol, glucose, and insulin were identified. Among them, the most common are peroxisome proliferatoractivated receptors (PPARs), sterol-regulatory elementbinding proteins (SREBPs), liver $\mathrm{X}$ receptors (LXRs), and forkhead box protein O1 (FOXO1) [34]. Recent studies have shown a strong relationship between the expression of miRNAs and the metabolic activity of critically ill patients. One of the most intensely researched species involved in lipid metabolism was miRNA-122 [35]. Other species involved in lipid metabolism include miRNA-33a and miRNA-33b [36]. Regarding the insulin metabolism, Baroukh et al. showed increased expression levels for miRNA-375 [37]. Another species involved in the biochemical pathways of insulin is miRNA-124a [37], in a strong relationship with miRNA-124a activity. $\mathrm{Lu}$ et al. showed elevated expression levels of miRNA-223, which is involved in glucose metabolism through SLC2A4 [38]. Also in relation to glucose, studies have revealed important implications of miRNA-29 [39]. Regarding OS production in critically ill patients, numerous studies report significant implications for the outcome of these patients. Bedreag et al., in a study of the influence of OS on the outcomes of critically ill polytrauma patients, reported strong and statistically significant correlations between OSblocking through antioxidant therapy and the decreased expression of specific biochemical markers, shortened ICU days, and decreased mortality [40]. Sepsis is a leading cause of death in the ICU $[41,42]$, due mainly to the associated pathophysiologies that these patients develop, which will ultimately lead to the development of MODS and finally to death. In septic patients, the metabolic status is significantly altered and the EE is completely changed. Feferbaum et al. conducted a study on REE in neonatal patients with sepsis. They reported a significant increase in $\mathrm{EE}$ from $49.4 \pm 13.1 \mathrm{kcal} / \mathrm{kg} /$ day to $68.3 \pm$ $10.9 \mathrm{kcal} / \mathrm{kg} /$ day in the acute phase of sepsis. Moreover, during the acute phase of sepsis, they revealed a marked increase in $\mathrm{VO}_{2}$ and correspondingly $\mathrm{VCO}_{2}$. Thus, they highlighted statistically significant differences $(p<0.01)$ for $\mathrm{VO}_{2}$ that increased from $7.4 \pm 1.9 \mathrm{ml} / \mathrm{kg} / \mathrm{min}$ to $10 \pm$ $1.5 \mathrm{ml} / \mathrm{kg} / \mathrm{min}$. The case of $\mathrm{VCO}_{2}$ was similar, showing a significant increase from $5 \pm 1.7 \mathrm{ml} / \mathrm{kg} / \mathrm{min}$ to $7.4 \pm$ 
Table 1 Clinical consequences due to severe metabolic imbalance

\begin{tabular}{ll}
\hline Metabolic imbalance & Observations \\
\hline Underfeeding & Negative energy balance associated with poor outcome of critically ill patients \\
& Nutrition intolerance is associated with a high mortality rate \\
& Hitting a specific caloric target for each patient is associated with improved \\
& Outcomes and lower mortality rates \\
& Overfeeding is associated with hypercapnia \\
& Excess nutrient administration is associated with lower survival rate \\
Overfeeding & A longer time on mechanical ventilation and in the ICU is reported \\
& Hyperglycemia and hypertriglyceridemia were highlighted \\
& A high number of cases of metabolic acidosis and hypertonic dehydration \\
& associated with overfeeding have been reported \\
& Associated with insufficient degradation of protein structures and malfunctioned \\
& mitochondria \\
& Accelerated muscle destruction \\
& Difficult biochemical and pathophysiological systems recovery in case of patients \\
Autophagy & Tith MODS \\
& The immune system is affected and sepsis is accelerated \\
& Affection of the endogen antioxidant system with augmented pro-oxidative and \\
proinflammatory status & A severe change in electrolyte balance is reported \\
& Fluid and sodium ions retention are associated with heart failure and respiratory failure \\
& \\
Re-feeding & [62, 63] \\
\hline
\end{tabular}

$1.5 \mathrm{ml} / \mathrm{kg} / \mathrm{min}$ [43]. Alberda et al. conducted a study on the relationship between the amount of administered protein and the clinical outcomes of critically ill patients. This trial included 2772 mechanically ventilated patients, who were then administered $1034 \mathrm{kcal} /$ day and $47 \mathrm{~g}$ protein. The study reported a significant decrease in the time spent on a mechanical ventilator and a significant decrease in mortality at 60 days [44].

Villet et al. conducted a similar study on the links between underfed critically ill patients and their outcome. In this study, EE monitoring was performed using electronic equipment based on indirect calorimetry. The results showed a strong correlation between mortality rates and the energy deficit of these patients [45]. Allingstrup et al. conducted a similar study on correlations between the nutrient doses administered and the outcomes of critically ill patients. Metabolic status monitoring was performed using a Deltatrac II (MBM-200, Datex-Ohmeda, Helsinki, Finland) and a CCM Express Indirect Calorimeter (MedGraphics, St. Paul, MN, USA). The study showed a significant decrease in mortality in patients who were administered a higher dose of proteins and amino acids [46].

\section{Energy demand evaluation and monitoring methods}

One of the most widely used methods for calculating energy demand in critically ill pediatric patients is represented by Schofield's predictive equations, based on a linear equation that includes variables such as the weight, height, and sex of the patient. It has been shown that in such patients, these predictive equations can have large errors due to the complexity of the associated pathophysiologies. van der Kuip et al. conducted a study on the EE monitoring of mechanically ventilated pediatric patients with sepsis, trauma, or major surgery. The study revealed significant differences between the methods used to predict EE. Thus, they have reported that the Schofield equation for EE cannot give a correct prediction in cases of critically ill patients, requiring further evaluation and monitoring methods for the metabolic status [47].

These results emphasize still more the importance of using electronic equipment for monitoring energy demand in these patients. The continuous monitoring of $\mathrm{EE}$ is based on the evaluation of $\mathrm{VO}_{2}$ and $\mathrm{VCO}_{2}$ using IC. An old system for monitoring the metabolic status of critically ill patients using IC is the Deltatrac II (DatexOhmeda, 2000, Helsinki, Finland). Unfortunately, this method is quite expensive and requires trained personnel to operate the equipment. A newer system is the gas exchange module for monitoring E-COVX, known as MCOVX (GE Healthcare/Datex-Ohmeda, Helsinki, Finland) [48-50]. McLellan et al. conducted a study on the metabolic monitoring of mechanically ventilated critically ill patients using M-COVX (Datex-Ohmeda, Helsinki, Finland). The study showed that M-COVX is highly accurate, increasing the interest in the integration of this 
module in the context of multimodal monitoring methods for critically ill patients [51].

Regarding the operating principle, E-COVX analyzes $\mathrm{VO}_{2}$ and $\mathrm{VCO}_{2}$ by the breath-by-breath method. Another important feature of this system is its high stability in monitoring mechanically ventilated patients with increased secretions or in the maneuvering and nursing of endotracheal intubation [10, 52, 53]. Briassoulis et al. conducted a study on the accuracy of the results obtained using E-COVX modules on mechanically ventilated critically ill patients with increased secretions. The study showed that the system reaches a steady state approximately $5 \mathrm{~min}$ after open endotracheal suctioning with high accuracy [54].

Kan et al. studied the effects of metabolic status on the outcome of critically ill patients. The patients included in the study were divided into three groups: underfed, who received less than $90 \%$ of the necessary nutrition; appropriate feeding, receiving nutrition with an error of plus or minus $10 \%$; and overfed patients, who received more than $110 \%$ of the necessary. Following the study, a significant improvement in hemodynamic status was reported in patients whose nutrition was individualized and related to their needs, reducing both the time of mechanical ventilation and the time in the ICU [55].

A high percentage of critically ill polytrauma patients require prolonged mechanical ventilation. A number of studies have shown that providing the needed energy to a mechanically ventilated critically ill patient is directly related to shorter mechanical ventilation time and to a shorter time spent in the ICU. Askanazi et al. proved that malnourished patients have a more prolonged mechanical ventilation time because the respiratory epithelium does not recover as fast and because there is a significant delay in restoring the functionality of the respiratory muscles [56]. On the other hand, Dark et al. proved that in critically ill patients who are receiving excessive alimentation exceeding their energetic needs, the mechanical ventilation time is also longer. In this situation, the increased mechanical ventilation time was explained by the increase in $\mathrm{VO}_{2}$ and the increase in blood gas imbalances, such as imbalance of the $\mathrm{PCO}_{2} /$ $\mathrm{PO}_{2}$ ratio [57]. A similar study was conducted by Bassili et al. and reported a significant increase in the time of mechanical ventilation in patients who did not receive optimal nutrition [58].

There are a few other EE-monitoring modules, but studies have reported lower accuracy of the EE values detected. Graf et al. conducted a study on various monitoring systems for EE. Deltatrac II (Datex-Ohmeda, Helsinki, Finland), CCM Express (Medgraphics), and Quark RMR (COSMED) were used in the study. They reported statistically significant differences in terms of result accuracy, with differences of up to $441 \mathrm{kcal}$ in the detected EE values [52].

\section{Conclusions}

The complex pathophysiologies associated with severe trauma lead to a significant decrease in the survival rate of critically ill trauma patients. The nutritional status of the patient is closely related to a series of specific pathophysiologies involved in the worsening of the clinical status and lowering of the survival rate of these patients. Monitoring of the metabolic status and optimizing the nutritional therapy according to the needs of each patient is necessary, as it contributes directly to shorter mechanical ventilation times, shorter ICU stays, lower costs, and lower mortality rates.

\section{Acknowledgements}

The authors are deeply grateful to Emergency County Hospital "Pius Brinzeu" Timisoara and Victor Babes University of Medicine and Pharmacy Timisoara for the full support of this article.

Funding

Not applicable.

Availability of data and materials

Not applicable.

\section{Authors' contributions}

$A F R, O H B$, and DS were responsible for the design and wrote the manuscript. $M P, L M B, A T S$, and ERS contributed to parts of the writing. SEP, AMS, CV and AFR were responsible for the design and revised the manuscript. All authors read and approved the final manuscript.

\section{Competing interests}

The authors declare that they have no competing interests.

Consent for publication

Not applicable.

Ethics approval and consent to participate

Not applicable.

\section{Author details}

${ }^{1}$ Faculty of Medicine, Victor Babes University of Medicine and Pharmacy, Str. Eftimie Murgu Nr. 2, Timisoara 300041, Timis, Romania. ${ }^{2}$ Clinic of Anaesthesia and Intensive Care, Emergency County Hospital "Pius Brinzeu", Bd. Liviu Rebreanu Nr.156, Timisoara 300736, Timis, Romania. ${ }^{3}$ Faculty of Pharmacy, Victor Babes University of Medicine and Pharmacy, Str. Eftimie Murgu Nr. 2, Timisoara 300041, Timis, Romania. ${ }^{4}$ Faculty of Dental Medicine, Victor Babes University of Medicine and Pharmacy, Str. Eftimie Murgu Nr. 2, Timisoara 300041, Timis, Romania.

Received: 23 December 2016 Accepted: 23 February 2017 Published online: 07 March 2017

\section{References}

1. Strnad M, Lesjak VB, Vujanović V, Pelcl T, Križmarić M. Predictors of mortality and prehospital monitoring limitations in blunt trauma patients. Biomed Res Int. 2015;2015:983409.

2. Lausevic Z, Lausevic M, Trbojevic-Stankovic J, Krstic S, Stojimirovic B. Predicting multiple organ failure in patients with severe trauma. Can J Surg. 2008;51:97-102.

3. Kotzampassi K, Kolios G, Manousou P, Kazamias P, Paramythiotis D, Papavramidis TS, et al. Oxidative stress due to anesthesia and surgical trauma: importance of early enteral nutrition. Mol Nutr Food Res. 2009;53:770-9.

4. Burkhardt M, Nienaber U, Pizanis A, Maegele M, Culemann U, Bouillon B, et al. Acute management and outcome of multiple trauma patients with pelvic disruptions. Crit Care. 2012;16:R163.

5. Keel M, Trentz O. Pathophysiology of polytrauma. Injury. 2005;36:691-709.

6. Bedreag $\mathrm{OH}$, Sandesc D, Chiriac SD, Rogobete AF, Cradigati AC, Sarandan M, et al. The use of circulating miRNAs as biomarkers for oxidative stress in critically ill polytrauma patients. Clin Lab. 2016;62:263-74. 
7. Bedreag $\mathrm{OH}$, Rogobete AF, Sarandan M, Cradigati AC, Papurica M, Dumbuleu MC, et al. Oxidative stress in severe pulmonary trauma in critical ill patients. Antioxidant therapy in patients with multiple trauma-a review. Anestezjol Intens Ter. 2014. doi:10.5603/AlT.a2015.0030.

8. Sandesc D. Oxidative Stress in the Critically III Polytrauma Patient. J Crit Care Med. 2015;1(3):81-2.

9. Huang $Y$, Cai $X, H u$ Y. The important role of microRNAs in lipid metabolism. Metabolism. 2013;62:e1-2.

10. Rousing ML, Hviid M, Pedersen $H$, Andreassen S, Pielmeier U, Preiser JC. Energy expenditure in critically ill patients estimated by population-based equations, indirect calorimetry and $\mathrm{CO}$-based indirect calorimetry. Ann Intensive Care. 2016;6:16.

11. Huber-Lang $M$, Kovtun $A$, Ignatius $A$. The role of complement in trauma and fracture healing. Semin Immunol. 2013;25:73-8.

12. Park GR. Molecular mechanisms of drug metabolism in the critically ill. Br J Anaesth. 1996;77:32-49.

13. Medina-gómez G. Best practice \& research clinical endocrinology \& metabolism mitochondria and endocrine function of adipose tissue. Best Pract Res Clin Endocrinol Metab. 2012;26:791-804.

14. Bellani G, Foti G, Spagnolli E, Milan M, Zanella A, Greco M, Patroniti N, Pesenti $A$. Increase of oxygen consumption during a progressive decrease of ventilatory support is lower in patients failing the trial in comparison with those who succeed. Anesthesiology. 2010;113(2):378-85.

15. Smallwood CD, Mehta NM. Gas exchange measurement during pediatric mechanical ventilation-agreement between gas sampling at the airway and the ventilator exhaust. Clin Nutr. 2013;32:988-92.

16. Tavladaki T, Spanaki A, Dimitriou H, Kozlov A, Duvigneau J, Weidinger A, et al. Bioenergetics and metabolic patterns in early onset severe sepsis or trauma. Intensive Care Med Exp. 2015;3:A43.

17. Terlecky SR. Peroxisomes, oxidative stress, and inflammation. World J Biol Chem. 2012;3:93

18. Luca L, Rogobete AF, Bedreag $\mathrm{OH}$. Oxidative stress and antioxidant therapy in critically ill polytrauma patients with severe head injury. J Crit Care Med. 2015;1:83-91.

19. Roberts CK, Sindhu KK. Oxidative stress and metabolic syndrome. Life Sci. 2009;84:705-12.

20. Miller A-F. Superoxide dismutases: ancient enzymes and new insights. FEBS Lett. 2012:586:585-95.

21. Papurica M, Rogobete AF, Sandesc D, Dumache R, Nartita R, Sarandan M, et al. Redox changes induced by general anesthesia in critically ill patients with multiple traumas. Mol Biol Int. 2015;2015:238586.

22. Horhat FG, Rogobete AF, Papurica M, Sandesc D, Tanasescu S, Dumitrascu V, et al. The use of lipid peroxidation expression as a biomarker for the molecular damage in the critically ill polytrauma patient. Clin Lab. 2016; 62(9):1601-7.

23. Bedreag $\mathrm{OH}$, Rogobete $\mathrm{AF}$, Sărăndan $\mathrm{M}$, Cradigati $\mathrm{A}$, Păpurică $\mathrm{M}$, Maria $\mathrm{O}$, et al. Oxidative stress and antioxidant therapy in traumatic spinal cord injuries. Rom J Anesth Int Care. 2014;21:123-9.

24. Bratu LM, Rogobete AF, Sandesc D, Bedreag OH, Tanasescu S, Nitu R, et al. The use of redox expression and associated molecular damage to evaluate the inflammatory response in critically ill patient with severe burn. Biochem Genet. 2016;54:1-16

25. Papurica M, Rogobete AF, Sandesc D, Dumache $R$, Cradigati CA, Sarandan M, Nartita R, Popovici SE, Bedreag OH. Advances in biomarkers in critical ill polytrauma patients. Clin Lab. 2016;62(6):977-86.

26. Rogobete AF, Bedreag OH, Popovici SE, Sas AM, Stan AT, Stoicescu ER, et al. Detection of myocardial injury using miRNAs expression as genetic biomarkers in acute cardiac care. J Cardiovasc Emergencies. 2016;2:169-72

27. Papurica M, Rogobete AF. The expression of nuclear transcription factor kappa B (NF-kB) in the case of critically ill polytrauma patients with sepsis and its interactions with microRNAs. Biochem Genet. 2016:54:337.

28. Rech MA, Mosier MJ, Zelisko S, Netzer G, Kovacs EJ, Afshar M. Comparison of Automated Methods Versus the American Burn Association Sepsis Definition to Identify Sepsis and Sepsis With Organ Dysfunction/Septic Shock in Burn-Injured Adults. J Burn Care Res. 2017. doi:10.1097/BCR.0000000000000504. Epub ahead of print.

29. Guerra RC, Zuñiga-muñoz A, Lans VG, Díaz-díaz E, Alberto C, Betancourt T, et al. Modulation of the activities of catalase, $\mathrm{Cu}-\mathrm{Zn}, \mathrm{Mn}$ superoxide dismutase, and glutathione peroxidase in adipocyte from ovariectomised female rats with metabolic syndrome. Int J Endocrinol. 2014;2014:175080.
30. Bjugstad KB, Rael LT, Levy S, Carrick M, Mains CW, Slone DS, et al. Oxidationreduction potential as a biomarker for severity and acute outcome in traumatic brain injury. Oxid Med Cell Longev. 2016;2016:6974257.

31. Grintescu IM, Vasiliu IL, Badica IC, Mirea L, Pavelescu D, Balanescu A, et al. The influence of parenteral glutamine supplementation on glucose homeostasis in critically ill polytrauma patients-a randomized-controlled clinical study. Clin Nutr. 2015;34:377-82

32. Albacker T, Carvalho G, Schricker T, Lachapelle K. High-dose insulin therapy attenuates systemic inflammatory response in coronary artery bypass grafting patients. Ann Thorac Surg. 2008:86:20-7.

33. Jeschke MG, Patsouris D, Stanojcic M, Abdullahi A, Rehou S, Pinto R, et al. Pathophysiologic response to burns in the elderly. EBioMedicine. 2015;2: 1536-48.

34. Rottiers $\mathrm{V}$, Näär AM. MicroRNAs in metabolism and metabolic disorders. Nat Rev Mol Cell Biol. 2012;13(4):239-50.

35. Esau C, Davis S, Murray SF, Yu XX, Pandey SK, Pear M, et al. miR-122 regulation of lipid metabolism revealed by in vivo antisense targeting. Cell Metab. 2006;3:87-98

36. Horton JD, Goldstein JL, Brown MS. Critical review. Most. 2002;109:1125-31.

37. Baroukh NN, Van Obberghen E. Function of microRNA-375 and microRNA124a in pancreas and brain. FEBS J. 2009;276:6509-21.

38. Lu H, Buchan RJ, Cook SA. MicroRNA-223 regulates Glut4 expression and cardiomyocyte glucose metabolism. Cardiovasc Res. 2010;86:410-20.

39. Pullen TJ, da Silva XG, Kelsey G, Rutter G. miR-29a and miR-29b contribute to pancreatic beta-cell-specific silencing of monocarboxylate transporter 1 (Mct1). Mol Cell Biol. 2011;31:3182-94.

40. Bedreag $\mathrm{OH}$, Rogobete AF, Sarandan M, Cradigati AC, Papurica M, Rosu OM, et al. Influence of antioxidant therapy on the clinical status of multiple trauma patients. A retrospective single center study. Rom J Anesth Int Care. 2015:22:89-96

41. Dumache R, Rogobete AF, Bedreag OH, Sarandan M, Cradigati AC, Papurica M, et al. Use of miRNAs as biomarkers in sepsis. Anal Cell Pathol. 2015;2015: 186716.

42. Corrêa TD, Jakob SM, Takala J. Platelet mitochondrial function in sepsis. Crit Care Horizons. 2015;1:31-41.

43. Feferbaum R, Leone C, Siqueira AA, Valenti VE, Gallo PR, Reis AO, et al. Rest energy expenditure is decreased during the acute as compared to the recovery phase of sepsis in newborns. Nutr Metab. 2010;7:63.

44. Alberda C, Gramlich L, Jones N, Jeejeebhoy K, Day AG, Dhaliwal R, et al. The relationship between nutritional intake and clinical outcomes in critically ill patients: results of an international multicenter observational study. Intensive Care Med. 2009;35:1728-37.

45. Villet S, Chiolero RL, Bollmann MD, Revelly J-P, Cayeux RNM-C, Delarue J, et al. Negative impact of hypocaloric feeding and energy balance on clinical outcome in ICU patients. Clin Nutr. 2016;24:502-9.

46. Allingstrup MJ, Kondrup J, Perner A, Christensen PL, Jensen $\mathrm{TH}$, Henneberg SW. Indirect calorimetry in mechanically ventilated patients: a prospective, randomized, clinical validation of 2 devices against a gold standard. J Parenter Enteral Nutr. 2016. doi:10.1177/0148607116662000

47. van der Kuip M, de Meer K, Oosterveld MJS, Lafeber HN, Gemke RJBJ. Simple and accurate assessment of energy expenditure in ventilated paediatric intensive care patients. Clin Nutr. 2004;23:657-63.

48. Ekbal NJ, Dyson A, Black C, Singer M. Monitoring tissue perfusion, oxygenation, and metabolism in critically ill patients. Chest. 2013;143:1799-808.

49. Ko SB. Multimodality monitoring in the neurointensive care unit: a special perspective for patients with stroke. J stroke. 2013;15:99-108.

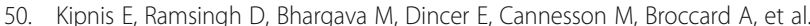
Monitoring in the intensive care. Crit Care Res Pract. 2012;2012

51. Mclellan S, Walsh T, Burdess A, Lee A, Lee A. Comparison between the Datex-Ohmeda M-COVX metabolic monitor and the Deltatrac II in mechanically ventilated patients. Intensive Care Med. 2002;28(7):870-6.

52. Graf S, Karsegard VL, Viatte V, Maisonneuve N, Pichard C, Genton L. Comparison of three indirect calorimetry devices and three methods of gas collection: a prospective observational study. Clin Nutr. 2013:32: 1067-72.

53. Sundström M, Tjäder I, Rooyackers $\mathrm{O}$, Wernerman J. Indirect calorimetry in mechanically ventilated patients. A systematic comparison of three instruments. Clin Nutr. 2013:32:118-21.

54. Briassoulis G, Michaeloudi E, Fitrolaki DM, Spanaki AM, Briassouli E, et al. Influence of different ventilator modes on $V_{\mathrm{O}_{2}}$ and $\mathrm{V}_{\mathrm{CO} 2}$ measurements using a compact metabolic monitor. Nutrition. 2009;25:1106-14. 
55. Kan MN, Chang HH, Sheu WF, Cheng CH, Lee BJ, Huang YC. Estimation of energy requirements for mechanically ventilated, critically ill patients using nutritional status. Crit Care. 2003;7:R108-15.

56. Askanazi J, Weissman C, Rosenbaum SH, Hyman Al, Milic-Emili J, Kinney JM. Nutrition and the respiratory system. Crit Care Med. 1982;10:163-72.

57. Dark DS, Pingleton SK, Kerby GR. Hypercapnia during weaning. A complication of nutritional support. Chest. 1985;88:141-3.

58. Bassili HR, Deitel M. Effect of nutritional support on weaning patients off mechanical ventilators. J Parenter Enter Nutr. 1981;5:161-3.

59. Singer P, Pogrebetsky I, Attal-Singer J, Cohen J. Comparison of metabolic monitors in critically ill, ventilated patients. Nutrition. 2006;22(11-12):1077-86.

60. Wischmeyer PE, Dhaliwal R, McCall M, Ziegler TR, Heyland DK. Parenteral glutamine supplementation in critical illness: a systematic review. Crit Care. 2014;18:R76.

61. Vanhorebeek I, Gunst J, Derde S, Derese I, Boussemaere M, D'Hoore A, et al. Mitochondrial fusion, fission, and biogenesis in prolonged critically ill patients. J Clin Endocrinol Metab. 2012;97:E59-64.

62. Marik PE, Bellomo R. Stress hyperglycemia: an essential survival response Crit Care Med. 2013:41:e93-4.

63. Preiser J, van Zanten AR, Berger MM, Biolo G, Casaer MP, Doig GS, et al. Metabolic and nutritional support of critically ill patients: consensus and controversies. Crit Care. 2015:19:1-11.

Submit your next manuscript to BioMed Central and we will help you at every step:

- We accept pre-submission inquiries

- Our selector tool helps you to find the most relevant journal

- We provide round the clock customer support

- Convenient online submission

- Thorough peer review

- Inclusion in PubMed and all major indexing services

- Maximum visibility for your research

Submit your manuscript at www.biomedcentral.com/submit
Biomed Central 